\title{
Văn hóa Doanh nghiệp - IBM Institute
}

\section{IBM Institute}

June 9, 2017

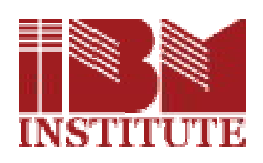

https://ibm.edu.vn/van-hoa-doanh-nghiep/ 


\section{NămởnoámDoanhomghiệp a}

\section{VĂN HOÁ DOANH NGHIỆP}

四 Khai giảng: Đang cập nhật

(1) Thời lượng: 16 tiết (4 buổi - 2 ngày)

1 Hình thức: Public hoặc In-house Training

『 Học phí: 2.200.000 đồng

๑ Địa điểm tổ chức:

- Tp. Hồ Chí Minh

- Bình Dương

- Vũng Tàu

- Cần Thơ

\section{ĐĂNG KÝ $\rightarrow$}

Hãy cùng IBM
chia sẻ với bạn
bè về khoá học
này!

Văn hoá doanh nghiệp là một yêu câu tất yếu của sự triển thương hiệu vì hình ảnh văn hóa doanh nghiệp sẽ góp phần quảng bá thương hiệu của doanh nghiệp. Văn hoá doanh nghiệp chính là tài sản vô hình của mỗi doanh nghiệp.

Yễu tố văn hoá luôn hình thành song song với quá trình phát triển của doanh nghiệp. Văn hoá doanh nghiệp là văn hoá của một tổ chức vì vậy nó không đơn thuần là văn hoá giao tiếp hay văn hoá kinh doanh, nó cũng không phải là những khẩu hiệu của ban lãnh đạo được treo trước lối vào hay trong phòng họp. Mà nó bao gồm sự tổng hợp của các yếu tố trên. Nó là giá trị, niềm tin, chuẩn mực được thể hiện trong thực tế và trong các hành vi mỗi thành viên doanh nghiệp.

Cốt lõi của văn hoá doanh nghiệp là tinh thần doanh nghiệp và quan điểm giá trị của doanh nghiệp. Trong cuốn sách Văn minh làm giàu và nguồn gốc của cải của TS. Vương Quân Hoàng, chúng ta đã được đề cập tới khái niệm giá trị. Giải thích một cách đơn giản, giá trị là một cái gì đó mà người ta cảm thấy quan trọng, có ích. Cụm từ "quan trọng" và "có ích lợi" là rất đáng lưu tâm trong xây dựng văn hóa doanh nghiệp. Bởi lẽ lãnh đạo công ty sẽ rất khó xây dựng văn hóa doanh nghiệp, nếu không bảo vệ ích lợi mà văn hóa doanh nghiệp đem lại. Nhân viên cần nhận thức được rằng việc đeo thẻ nhân viên, mặc đồng phục là thể hiện sự tự hào là thành viên của công ty, và có ích cho công việc của họ chứ không phải để làm quảng cáo. 


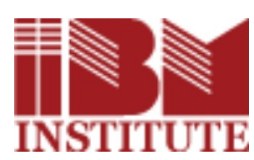

Một câu hỏi được đặt ra rằng, vậy những giá trị nào là hợp lý và giá trị

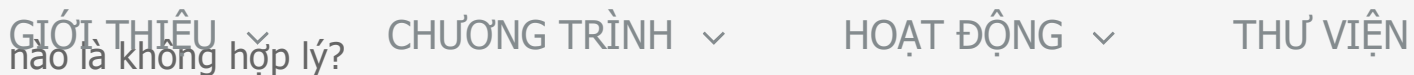

Thông qua các nghiên cứu về vai trò và tầm quan trọng của việc mong

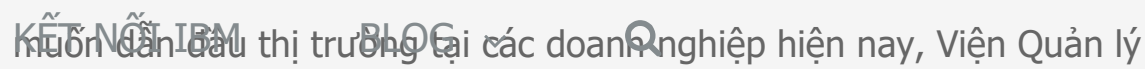
kinh doanh quốc tế IBM triển khai chương trình Văn hóa doanh nghiệp với những chia sẻ kinh nghiệm thực tiễn, giàu tính ứng dụng của giảng viên là các chuyên gia tư vấn và giảng dạy giàu kinh nghiệm hiện nay.

ص Mục tiêu chương trình

nội dung chương trình

\section{Chuyên gia}

\section{Brochure}

\section{Mục tiêu khoá học}

Khóa học nhằm mục tiêu trang bị cho học viên những kiến thức và kỹ năng cần thiết như sau:

- Nắm bắt được vai trò, chức năng, của văn hóa doanh nghiệp.

• Nắm vững được các nguyên tắc ứng xử, giao tiếp

- Nắm vững các cách thức để có thể tự mình cùng với Ban lãnh đạo công ty xây dựng được "một nền văn hóa mạnh và phù hợp" cho công ty của mình;

\section{Đối tượng tham dự}

- Các Giám đốc, các cấp quản lý hiện tại đang hoạt động tại các doanh nghiệp hoặc các cá nhân đang mong muốn khởi sự kinh doanh. 
bắt được các quy tắc ứng xử trong doanh nghiêp, bao gồm:

\section{GIỚI THIÊU $\vee$ CHƯONG TRİNH $\vee \vee \quad H O A T$ ĐỘNG $\vee$}

- Văn hóa trong giao tiếp chào hỏi (cách chào hỏi, cách thức bắt tay v.v.)

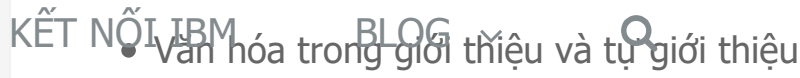

- Văn hóa trong sử dụng danh thiếp (sử dụng, trao đổi danh thiếp v.v.)

- Văn hóa nói chuyện

- Văn hóa ứng xử với khách hàng, đối tác (trong nước, ngoài nước v.v.)

- Văn hóa ứng xử với đồng nghiệp (lãnh đạo - nhân viên, nhân viên - nhân viên v.v.)

- Văn hóa trong giao tiếp qua điện thoại

- Văn hóa trong làm việc (vệ sinh nơi làm việc, tác phong v.v.)

- Văn hóa xử lý, giải quyết công việc

- Văn hóa hội họp (nghi thức hội họp, chỗ ngồi trong hội họp v.v.)

- Văn hóa tổ chức hoạt động ngoài công việc (bố trí chỗ ngồi khi dự tiệc, văn hóa dự tiệc, cách thức ngồi trong xe ô tô v.v.)

- Quy tắc đạo đức nghề nghiệp (chuẩn mực đạo đức nghề nghiệp, quan hệ nội bộ, quan hệ bên ngoài v.v.)

Phạm Hữu Ái

Quốc (MBA)

Chi Cục Thuế

Thuận An,
Trân Thị Thúy Trang (MBA)

Tổng Lãnh Sự

Australia,
Trân Thị Thiên Quyên (MBA)

Giám đốc chi

nhánh Prudential,
Nguyễn Xuân

Cương (MBA)

Cán bộ Quản lý -

Hội sở BIDV, 


\section{冓 \\ INSTITUTE}

chuyên đề đều đánh

trong khoá Quản trị

giờ cô độc trong quá

phương diện học

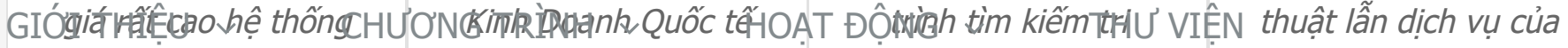

hỗ trợ học thuật

nghiêm túc và chu

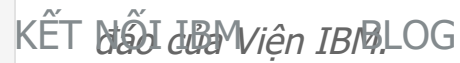

Tuy công việc bận

rộn nhưng chúng tôi

đều có thể học tập

bất cứ lúc nào thuận

tiện nhất." tại Viện IBM giúp tôi

tư duy một cách chủ

v độnghơn và hành

động có hệ thông

hơn trong công việc.

15 tháng học ở đây

trôi qua quá nhanh!" thức khi họ tại Viện

IBM. Trong môi

trường gắn kết đó,

học viên chúng tôi

luôn có điều kiện

giao Iưu, trao đổi ý

kiến và quan trọng

nhất là luôn có Viện

lắng nghe."
Viện. Có thể nói, từng chuyên đề tại

Viện IBM đã giúp tôi theo kip chương trình Thạc Sĩ mà tôi đang theo học với người nước ngoài. Xin cảm ơn nhiệt huyết của các thành viên IBM!"

\section{Related Posts}




\section{$\overline{1} \mathbb{N}$ \\ INSTITUTE}

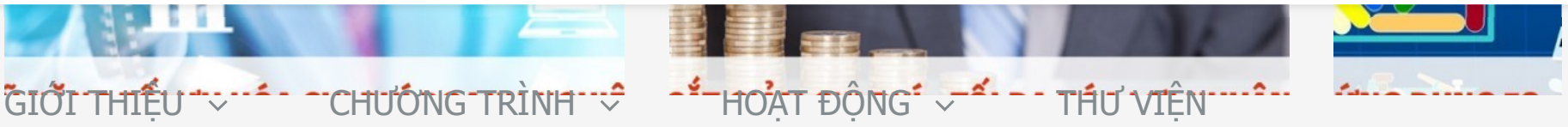

KÊTT NỐI IBM BLOG $\vee \quad Q$

\section{TRỤ SỞ CHÍNH}

224 Điện Biên Phủ, Phường 7,

Quận 3, TP HCM

Phone: 028.22.468.468

Email: info@ibm.edu.vn

Web: www.ibm.edu.vn

EDUTRUST - IBM HÀ NỘI

Tầng 5 Tòa nhà HKC - Số 285 Đội

Cấn, Ba Đình, Hà Nội

Phone: Tâng 5 Tòa nhà HKC - Số

285 Đội Cấn, Ba Đình, Hà Nội

Mobile: 0968808687

Email: info@edutrust.edu.vn
IBM - BÌNH DƯƠNG

f

Tầng 4, Tòa nhà Biconsi, đường

số 01, TTTM Bình Dương Square,

Phường Phú Lợi, Thủ Dầu Một,

Bình Dương

Phone: 0935141138

Email: tramdtb@eodc.edu.vn

Web: www.ebdm.edu.vn

IBM - VŨNG TÀU

102A, Lê Hồng Phong, P4, Tp

Vũng Tàu

Mobile: 0919.38.80.66

Email: tamnv@ibm.edu.vn

Web: www.ibm.edu.vn 
Tài liệu tham khảo:

[1] Đào Duy Anh. (1938). Việt Nam văn hóa sử cương. Quan Hải Tùng Thư, Huế (Imprimerie du Mirador).

[2] Vương Quân Hoàng. (2007). Văn minh làm giàu \& Nguồn gốc của cải. Nxb Chính trị Quốc gia, Hà Nội. 